\title{
New Interface Protocol to Connect Multiple Bank Networks from a Single Outlet
}

\author{
Aaditya Prakash \\ Infosys Limited \\ Pune, India
}

\author{
Rajan K Jha \\ Infosys Limited \\ Pune, India
}

\begin{abstract}
We propose an innovative interface protocol that will allow an access to multiple banks from a single outlet. This will enable a single branch to serve customers of several banks. This will in essence deleverage infrastructure of branch from banking business, allow banks to focus on service and product and not infrastructure, which is not its core competency. Having common branch will drastically reduce the number of branches required for given population and area; this will reduce operational cost of banking by manifolds.

Protocol we propose uses dynamic network switching of the multiple networks to allow the common interface to access the API of different participating banks. We propose a scalable model which could harness Cloud computing if the load on the infrastructure is high. We have also given justification for the need of Cost saving for bank branches and potential benefits of implementing the proposed model.
\end{abstract}

\section{General Terms}

Networking, Interface, Communication Protocol

\section{Keywords}

Infrastructure Protocol, Banking Interface, Low Cost Banking.

\section{INTRODUCTION}

Banking business has always depended upon its branches to propagate its business. Bank's branches have always been the most important Point-Of-Sale and Point-Of-Contact for its customers. Even with the advent of mobile banking (mBanking) and Internet Banking (eBanking), branches are driving the majority of its transactions.

Banks have spread their network and reach by opening its branches across the country. Most national banks have branches in all major cities and in few smaller towns and some in remote and rural areas. Most of the branches in rural areas are not viable and profitable to the banks (Ignacio, 2009 [1]) but they still operate them for repute and accolade. Cost of operating non-viable branches percolates as high cost on per transaction of the Bank. This high cost becomes a deterrent towards inclusion of banking for all especially people at the lower strata of social pyramid.

Due to severe lack of basic infrastructure in rural and semiurban areas the cost of installing a branch increases manifolds.
Internet, electricity, roads, telephone, sanitation, health are yet to reach all over the country [2]. Furthermore the lack of wide participation and awareness causes lack of critical mass which renders branch banking in villages a non-profitable business.

So there is a need for confluence with respect to infrastructure sharing. Lack of any technological provisions along this path has been a hindrance towards this move. We propose a system to overcome this by enabling possibility of multibank branch model. This system conceptualizes single window outlet for operation on multiple banks. This system will be a new paradigm in banking where banks will focus and compete on services and product; de-leveraging from infrastructure development and its costs. Using this system the potential to reduce overhead cost is immense. Lower cost banking will have greater inclusion which is paramount to social and economic inclusive growth of the country.

\section{EXISTING SYSTEM}

Currently banks have several branches across the country and have also introduced eBanking and very limited features of mBanking. Lack of growth in banking is clear evidence that current system and the new measures haven't done well in the task of including the masses [3]. Slow adaption of technology by both consumers and banks has been the reason for nonproliferation of advancements of technology.

\subsection{Cost of starting and operating branches}

Banking is a heavy infrastructure dependent business. It uses cross platform domains and several layers of technological hierarchy. Due to stringent security requirements and intricate compliance issues the cost of infrastructure surges manifolds. Ignacio (2009) has done detailed analysis of cost of opening and running a branch [1].

As we can see from the data above, the cost is relatively high and also imparts an entry barrier for the possible new entrants. Since branches are the focal point of banking there is no way that in current scenario banks will be able to do away with branches at all. While some banks like ICICI have started branch free banking, where accounts are not linked to any branch and all the operations on the account are done on virtual space, the number of operations is very limited and cannot become a substitute of a regular savings or current account. Thus the only solution to current issue would to drastically reduce the overhead cost of operating a branch 


\begin{tabular}{|c|c|c|c|c|}
\hline & & Branch based & $\begin{array}{l}\text { POS based agent } \\
\text { banking }\end{array}$ & $\begin{array}{l}\text { Cell phone based } \\
\text { agent banking }\end{array}$ \\
\hline \multirow[t]{4}{*}{$\begin{array}{l}\text { Fixed costs } \\
\text { per outlet. }\end{array}$} & Startup cost per outlet & $₹ 30,00,000$ & $₹ 1,00,000$ & $₹ 25,000$ \\
\hline & Useful life & 10 years & 3 years & 3 Years \\
\hline & $\begin{array}{l}\text { Operating cost per } \\
\text { month per Outlet }\end{array}$ & $\begin{array}{l}₹ 4,00,000 \\
10 \text { Salaries, rent, office } \\
\text { maintenance }\end{array}$ & $\begin{array}{l}\text { ₹ } 15,000 \\
\text { Maintenance and } \\
\text { supplies(e.g. paper, } \\
\text { marketing material) }\end{array}$ & $\begin{array}{l}₹ 2500 \\
\text { Marketing materials only }\end{array}$ \\
\hline & $\begin{array}{l}\text { Max transactions per } \\
\text { outlet per month }\end{array}$ & $\begin{array}{l}18000-7 \text { tellers, each } \\
\text { doing } 10 \text { transactions } \\
\text { per hour, } 8 \text { hours per } \\
\text { day, } 5 \text { days a week. }\end{array}$ & $\begin{array}{l}3000 \text { - } 1 \text { terminal, } 10 \\
\text { transactions per hour, } \\
10 \text { hours a day, } 30 \\
\text { days a month. }\end{array}$ & $\begin{array}{l}3000 \text { - } 1 \text { terminal, } 10 \\
\text { transactions per hour, } 10 \\
\text { hours a day, } 30 \text { days a } \\
\text { month. }\end{array}$ \\
\hline \multirow[t]{2}{*}{$\begin{array}{l}\text { Variable } \\
\text { costs per } \\
\text { transaction. }\end{array}$} & $\begin{array}{l}\text { Communication cost } \\
\text { per transaction. }\end{array}$ & $\begin{array}{l}₹ 0.50 \\
\text { Minimal charges for } \\
\text { uploading from IT } \\
\text { system. }\end{array}$ & $\begin{array}{l}₹ 2.50 \\
\text { Equivalent of } 1 \text { SMS } \\
\text { per transaction. }\end{array}$ & $\begin{array}{l}₹ 7.50 \\
\text { Equivalent of } 3 \text { SMS per } \\
\text { transaction. }\end{array}$ \\
\hline & $\begin{array}{l}\text { Agent commission } \\
\text { per transaction. }\end{array}$ & - & $₹ 5$ & $₹ 5$ \\
\hline \multirow[t]{3}{*}{$\begin{array}{l}\text { Fixed costs } \\
\text { per new } \\
\text { customer. }\end{array}$} & $\begin{array}{l}\text { Customer acquisition } \\
\text { cost. }\end{array}$ & $\begin{array}{l}₹ 250 \\
\text { Cost of handling directly } \\
\text { at branch. }\end{array}$ & $\begin{array}{l}₹ 100 \\
\text { Processing cost and } \\
\text { sign-up commission } \\
\text { paid to agent. }\end{array}$ & $\begin{array}{l}\text { ₹ } 100 \\
\text { Processing cost and sign- } \\
\text { up commission paid to } \\
\text { agent. }\end{array}$ \\
\hline & $\begin{array}{l}\text { Customer } \\
\text { credentials(card) }\end{array}$ & $\begin{array}{l}₹ 250 \\
\text { Half the customers get a } \\
\text { bank card. }\end{array}$ & $\begin{array}{l}₹ 500 \\
\text { Card issuance and } \\
\text { maintenance costs. }\end{array}$ & $\begin{array}{l}₹ 10 \\
\text { Over the configuration of } \\
\text { phone. }\end{array}$ \\
\hline & $\begin{array}{l}\text { Avg. Customer } \\
\text { lifetime. }\end{array}$ & 36 months & 36 months & 36 months \\
\hline $\begin{array}{l}\text { Back Office } \\
\text { costs. }\end{array}$ & $\begin{array}{l}\text { Back office per } \\
\text { customer per month. }\end{array}$ & $₹ 15$ & $₹ 15$ & $₹ 15$ \\
\hline \multicolumn{2}{|c|}{ Revenues to bank. } & $\begin{array}{l}\text { 4\% p.a. interest spread + } \\
\text { ₹ } 25 \text { Per transaction. }\end{array}$ & $\begin{array}{l}4 \% \text { p.a. interest spread } \\
+₹ 25 \text { Per transaction. }\end{array}$ & $\begin{array}{l}4 \% \text { p.a. interest spread }+ \\
₹ 25 \text { Per transaction. }\end{array}$ \\
\hline \multicolumn{2}{|c|}{$\begin{array}{l}\text { Customer cost per transaction (not } \\
\text { borne by provider) }\end{array}$} & $\begin{array}{l}₹ 25 \text { bus ticket }+2 \text { hours } \\
\text { travel and queuing time }\end{array}$ & 30 minutes total time. & 30 minutes total time. \\
\hline
\end{tabular}

Table 1: Cost of Starting and Operating a branch (Data averaged from several developing countries) ${ }^{[1]}$ 
While India has seen a rapid growth of telecommunication and mobile usage, surprisingly the adaption of mBanking has been minimal. Dr. K. C. Chakrabarty, Deputy Governor RBI, points out that mobile banking has not been a very successful venture. There are 400,000 transactions / month, out of which 300,000 is contribution of a single bank, while some banks have as low as 2 transactions /month. Mobile banking has suffered also due to inability of banks to converge on single platform, as different mobile sets use different technology. Also as a virtual device it is limited in the number of operations it can do. There is no possibility of complex banking transactions as well as those transactions involving several stages and possibly some documentation.

Internet Banking has certainly seen some success amongst urban people, where already the density of branches and other POS services are high. Whereas the rural and semi-urban area, which still houses the majority of Indians, remain bereft of eBanking due to lack of Internet Infrastructure. Poverty and illiteracy are also to blame for the lack of dispersion of internet, which still requires some sophistication, extra devices and working knowledge of English.

\subsection{Low cost ATMs and Other Innovations}

ATMs have been a major force in reducing the operating cost of branches for banks operating in urban areas and with high overhead cost. Rural banks and cooperative banks have mostly stayed away with ATM due to its very high cost of initial setup and other security issues. Dependency on internet has led to very limited growth of ATM in rural areas. While many innovations have been introduced in this area to reduce the cost of ATM (Karunanayake 2008) [4], the growth of rural ATMs has stagnated. While the people in rural area still prefer human contact, mostly due to ignorance and lack of sophistication deters them from using ATM. Low cost ATMs, introduced by Karunanayake [4], called mATMs depends upon external agents and propensity to trust an unknown person in developing countries has been found to be very low[5].

Seth et al (2006) introduced a model for low cost internet kiosk [6], which would provide a running bus service to connect to kiosk's which will be laden with banking interface. In his own words, while the system does great work in reaching the most rural areas but the overhead cost of transactions, given the very low number of transactions in rural and semi-urban areas, doesn't actually decrease the current cost model.

\section{PROPOSED MODEL}

While it has been shown that even low cost ATM or Internet Kiosk cannot wholly substitute a Branch, it suffices to say that a lower operating cost of branches would solve the majority of cost related problems and help spread of banking.

We propose a model and a protocol which will allow an external agency, either an independent body, consortium of banks, financial cooperative societies or government institutes to access the banking application of several banks from a single terminal. This will result in merging of branches of different banks and evolve as a single window outlet to access all (or almost all) the banking functionalities. This system is totally different from "Agent Banking", where agents only deal with small cash deposits and withdrawals and are tied to a single bank; our system allows a holistic banking and functions as a branch for all participating Banks.

\subsection{Architecture}

Banking industry has in years grown to introduce lot of standardization with protocols and messaging. Some of the well knows are:

\section{EBICS - Transmission Protocol \\ SEPA - Clearing Protocol \\ FIX - Communications Protocol}

\section{SWIFT - Network Protocol}

Our proposal could be classified as 'Infrastructure Protocol', since we enable the merging of basic infrastructure needed to run a branch.

While Banking Software have in general similar operations, like opening account, doing cash transactions, issuing cheques/DD/Bank guarantee, closing account etc., most of the banking software providers have developed lot of menus/operations which are unique to their platform. Banks also have lot of customized menus and operations catering to their specific products and requirements.

The Interface will have repository of those menus, basically forms which are used to submit information to the banking API. Depending upon the level of similarity either it could use same forms, similar forms (which dynamically change depending upon the Bank ID chosen) or completely separate forms catering to specific Banks.

Local Server caters to all transaction requests. On the first initiation of request, it will ask for authentication and a secure channel for the given bank. If none exists, it will use low cost model of establishing a secure channel (explained in detail later in this paper). Interface uses Public Key and/or RSA authentication to establish a secure channel. The DHCP client will provide the configuration needed to connect to Bank Network. Private DNS will resolve the bank IP based on the Bank ID provided from the network.

Strong firewall will accept all the incoming messages to prevent any unauthorized and alien data. Since we are dealing with multiple bank networks there is a need to manage the data so that the terminal network is not overloaded, this is achieved using 'Message Queue Management'. This could be scaled to different layers as needed 


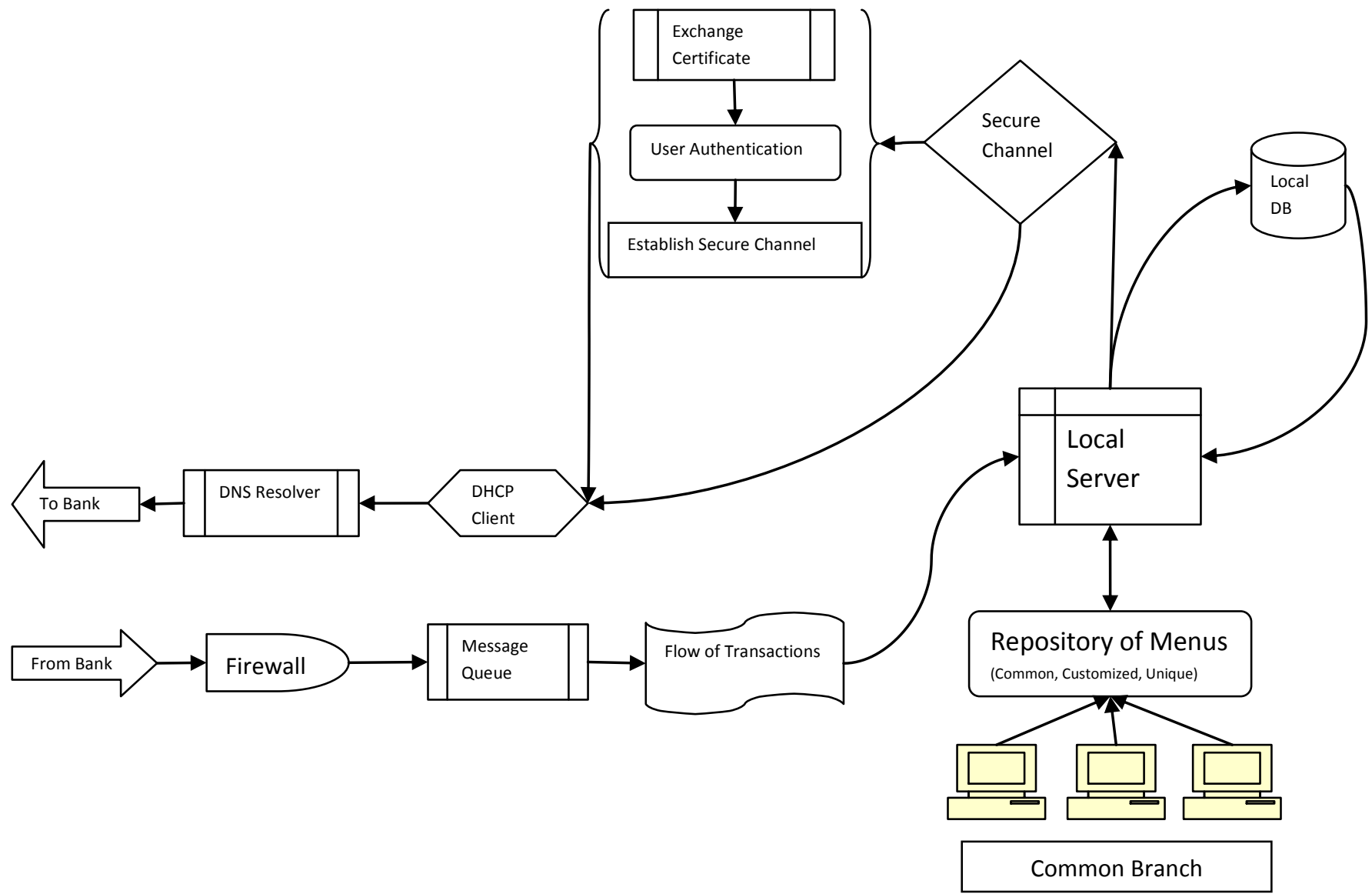

Figure 1: Block Diagram of the proposed Interface Protocol

Once the secure channel is established between the requesting terminal and the requested Bank, any number of uninterrupted transactions can flow. All the acknowledgements and data feeds will move seamless across bank's DB and the local server. Local server will store all the data sent and received into a local DB for the audit purposes

The flow of transaction - from entry to final record in database is given in the Figure 2.

\subsubsection{Network Switch}

While traditionally banks have restricted the access to its server to only its physical terminals, slowly banks have been accepting the idea of allowing limited or nominally limited access from terminals which may not be its own. Our model uses dynamically typed requests to open a bank's network. It allows it to connect to multiple networks and still be customizable.

API in our model for dynamically switching the networks is given below. This API could be customized for different scenario and the number of banks in the pool.

createNetworkSwitch - enables the switch to connect to a network

\section{- EnableDhcpService}

- EnableDnsService - this will be a private DNS an not a public one
- GetSourceNatService

- MovePortService

- ConnectVpnService

- GetFirewallService

- ThroughGatewayService

GetBankId: to fetch the Bank details (opens the channel for further communication)

- updateNetworkSwitch - To allow the on-the-fly network updates.

- BankId: Obtained from CreateNetworkSwitch

Here other methods from CreateNetworkSwitch could be added

\section{deleteNetworkSwitch}

- BankId: Deletes the established network.

\section{listBankNetworks}

- GetBankState: Provides the current state of a Bank network

On the basis of the load the Interface terminal could use NaaS (Network as a Service) and IaaS (Infrastructure as a Service) to scale up using the Cloud offering. This will help in keeping the in-house infrastructure to minimum while allowing to cater to high demands on special days and holidays. 
Gonçalves et al (2011) [6] introduced a novel way to scale infrastructure informatics to harness the power and affordability of cloud computing. Since the Network API above could run on multiple clusters and different networks, without disturbing already connected network, simple Map/Reduce program will enable the interface to scale up the banking transaction demand keeping the cost to minimal.

\subsubsection{Security}

In banking like in other business while cost and profit are the bottom-line, security can never be compromised. While keeping the cost to minimal - security measures have to be stringent. Since the model implies that some of the features of bank's server are accessed from outside the 'orthodox' bank network more security measures at different layers have to be applied. We propose the implementation of 'Low Cost secure transaction model' introduced by Munjal et al (2009) [8]. While keeping the cost low, the model proposes a very strong security model.

Certificate Exchange and Mutual Authentication and Session Key establishment ensures that there is no need for persistent connection, mutual trust between Bank and Interface has been established, and also infrastructure requirement is reduced.

\subsubsection{Setup and Trust}

The interface provider could be any third party, working in a franchise model, a cooperative society (which is not directly linked to any particular bank), NGOs which work in financial inclusion program, a consortium of banks (collaborating to bring down their overhead cost) or a government statutory body working for financial programs.

This provider would necessarily have to sign a 'Memorandum of Understanding' to partake into this venture. It may also need to provide a financial backing/security (if it is not nongovernmental or not affiliated to bank body).

While there is no need for the provider to have a working a/c with all the banks associated, as required for an 'Agent Banking' but having so would help the provider facilitate multibank transactions (without the invoking RTGS/NEFT)

It is paramount that the provider should not be a stake holder exclusively in a single bank or an entity of a single bank to avoid 'anti-trust' and competition issues.

\section{NEW PARADIGM}

Banks have come to be seen not only as an enabler of 'banking transactions' but also as structure of society. Our paper proposes a model which would render the visible part of the bank to minimal. Thus this beacons the new paradigm in banking. While moving away from infrastructure of branches will allow the banks to focus on providing innovative banking products and better services it would be safe to say some resistance, especially from old-timers, would be expected. There is a need for banks to bring about more customized and innovative products, innovation in banking services is long overdue and freeing up bank's need to worry and invest in infrastructure and expansion will allow it to do the same.

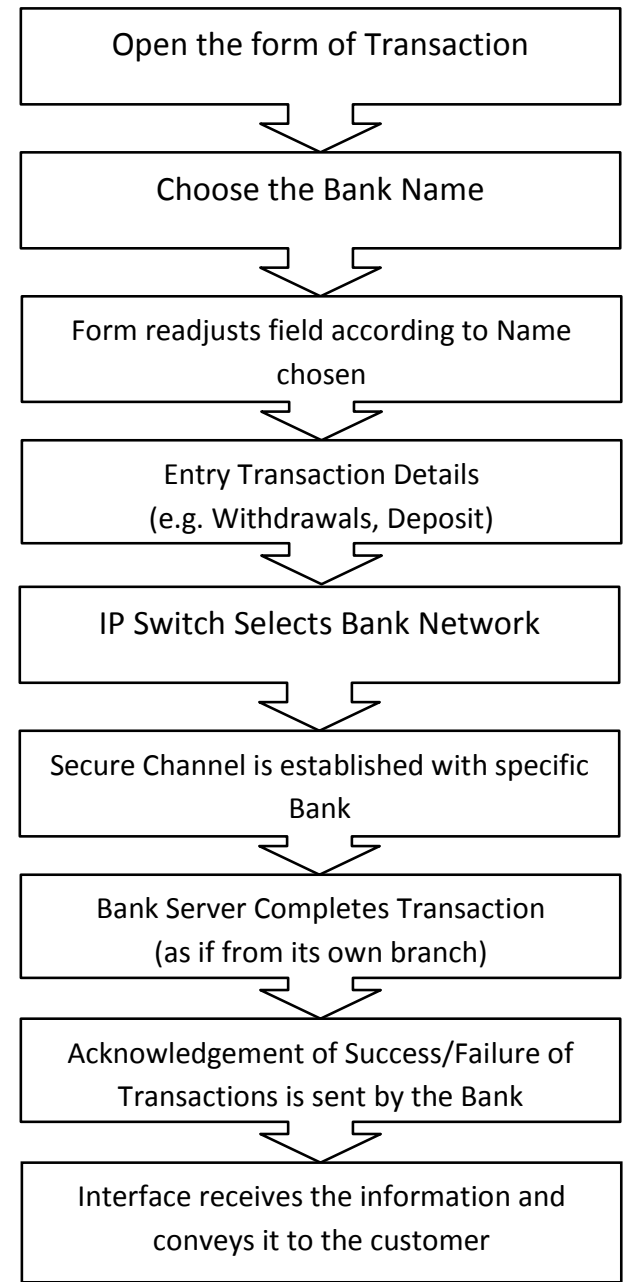

Figure 2 : Flow of Transactions in the proposed Interface

\subsection{Examples of successful sharing of Infrastructure}

Banking in general may not have precedence of sharing infrastructure but other sectors in the past have done so. Primarily because of very high entry barrier, for e.g. laying optic fiber cables for Internet, lots of ISPs have successfully ventured into 'Memorandum of Understanding' to share the infrastructure and network. Same goes for Broadcast and Television companies which share the satellite and sometimes even transmitting/receiving antennas. Recently Telecom has seen surge in infrastructure sharing [7], especially with towers and sometimes even with channels.

\subsection{Evidence of acceptance of possible infrastructure sharing among banks}

Due to severe lack of banking penetration among the masses, only $40 \%$ of people have checking account and only $5.2 \%$ villages have banking access and only $13 \%$ have ATM card [3], some of the government agencies have been trying to instill cooperation among banks. 


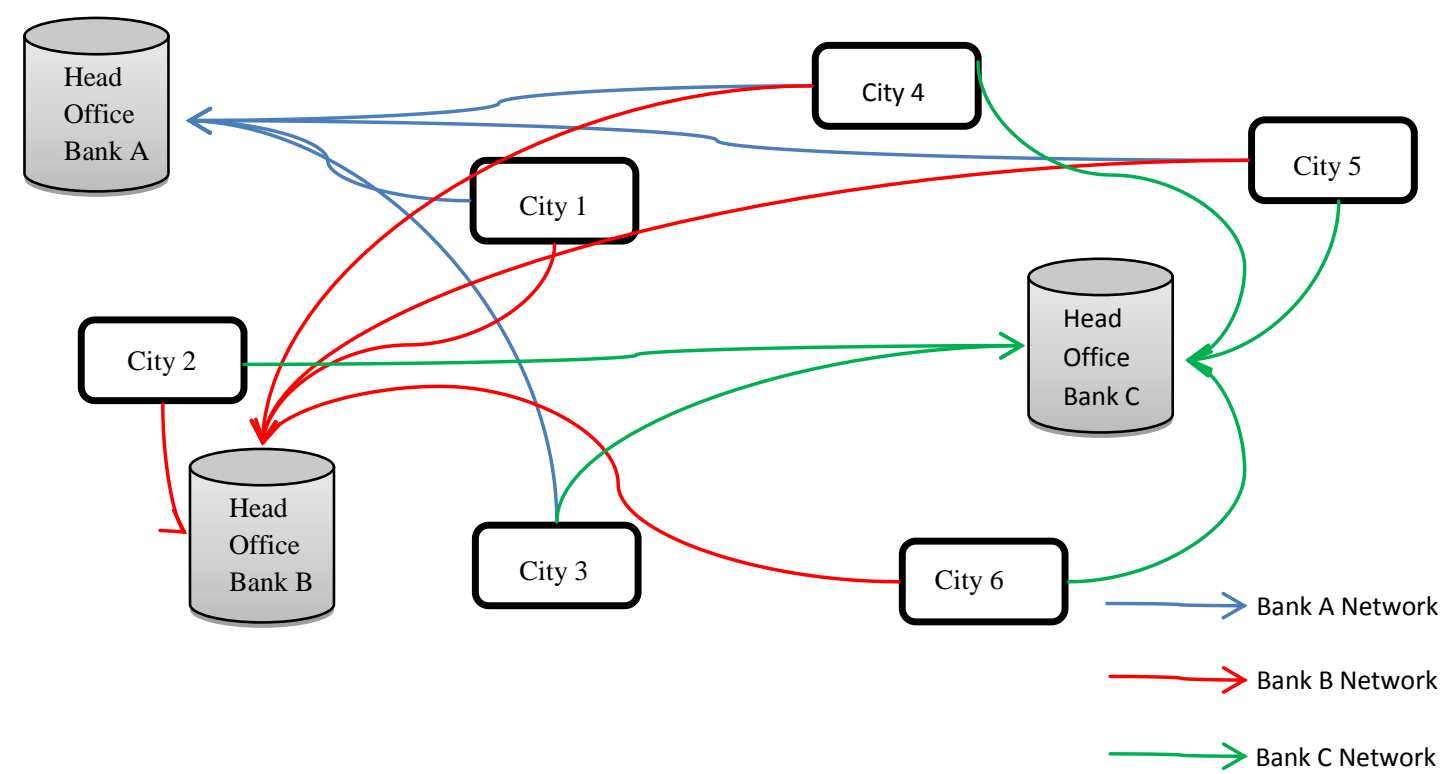

Figure 4 : Layout of Network of Banks and its Branches as its today

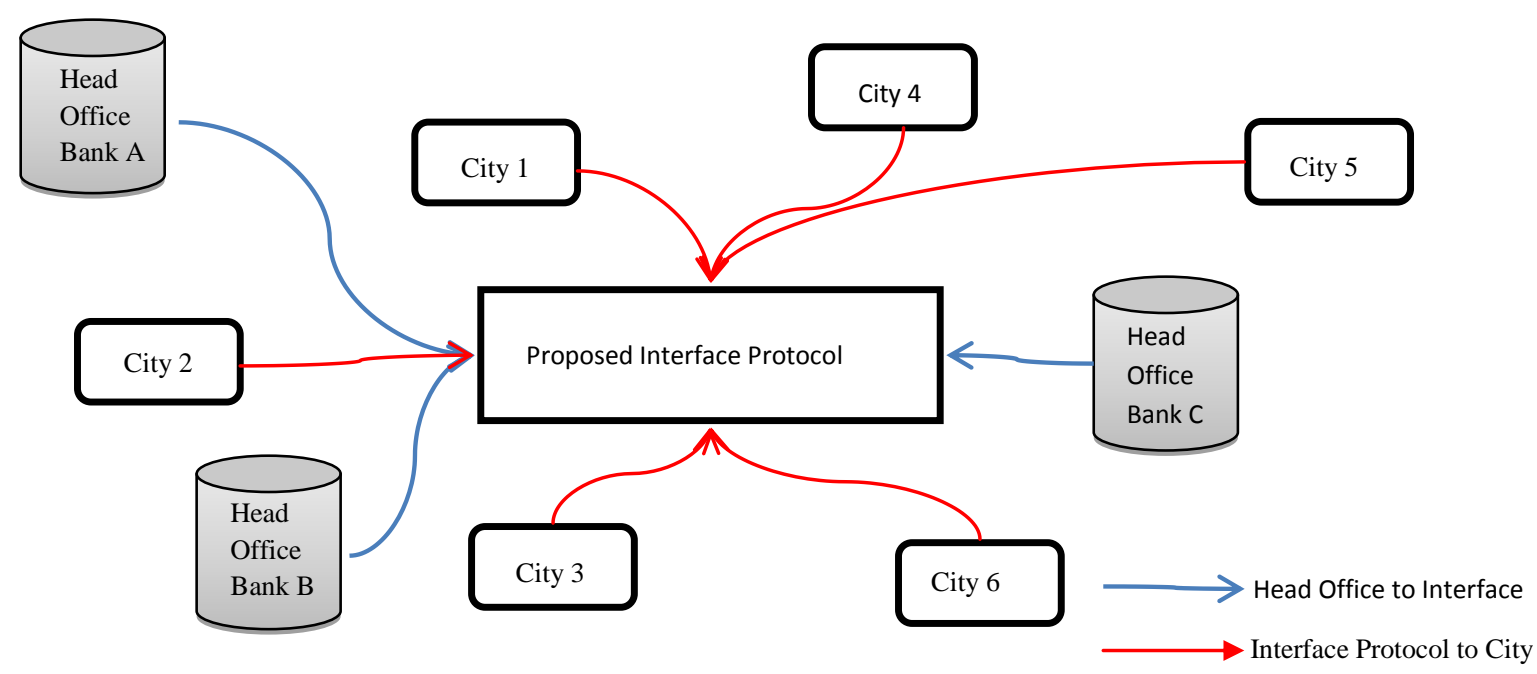

Figure 4 : Layout of Network of Banks and its branches under the proposed Interface protocol

RBI has allowed 'Business Correspondents' (Banking Agents) to take in more active role but have severely limited the possibility of scaling up this practice by not allowing NBFCs to participate. An Independent agent will always have limitation in terms of liquidity and infrastructure.

NABARD has started an initiative wherein it sponsors the CBS (Core Banking Solution) for the rural and cooperative banks since these banks do not have financial capability to adapt high end technologies and were losing out to private and commercial banks. While NABARDs attempt to reduce the operating cost of rural banks is commendable, in the having a common CBS does reduce the overall cost but it is taking undue cost on its own papers. These rural and cooperative banks would rather do well by collaborating with existing commercial banks to share infrastructure (using our proposed model), this will lead to no extra cost and hopefully will be able to keep small banks afloat in tough times.

\section{BENEFITS}

While there are several advantages of the proposed model, accessibility, scalability, wide reach, low entry barrier, liquidity management and standardization in banking, the most imperative advantage is the "Cost Factor".

\subsection{Reduction in Cost}

As described above in section 2.1 there are several factors that lead to high cost in opening and operating a branch. A common interface and single branch will solve most of the cost factors because there will be reduction of number of networks (branches connecting to head offices) by $\mathrm{N}$ factorial 
$[\mathrm{O}(\mathrm{n} !)]$, where $\mathrm{N}$ represents the number of nodes (cities/villages/towns). It has also been studied in game theory that competing for customers could lead to 'Tragedy of Commons', where each participant effectively earns much less than their social optimum [10][11].

\subsubsection{More branches at same cost, higher transactions at lower cost}

Since the model reduces the cost of opening and running a branch, much more branches can be opened for the same infrastructure budget. Having more branches and including more people in the banking umbrella will have a 'social network' effect wherein there will be exponential demand in banking operations. Experiments by Burgess et al (2003) [12], showed a rapid growth in rural banking when it involved social formations. There is clear evidence that the number of branches is still very low [2] and possibility of having more and new branches is abundant.

\subsection{Scalable Model}

When the network is dissociated from the Infrastructure there is potential to allow multiple networks on same infrastructure [13]. This allows for scalable model since the number of communicating node is not limited to one channel/mode of the network.

As the number of transactions, across all banks, grow it will make the branches viable even in rural and sparser areas (see Figure $3 \& 4$ ) since the 'economies of scale' will allow it to keep the operating cost at lowest margin. As discussed in the section 3.1.1 Network Switch, this model will allow the usage of Network as a Service (Naas) and Infrastructure as a Service (IaaS) to build upon the scalability. This level of scaling may not be required in rural and remote areas, but since the model could easily be used in cities and densely populated suburbs, the ability to use Hadoop clusters will greatly reduce the amount of upfront infrastructure investments.

\subsection{Reach and Nominal Branches}

The population is very heterogeneously spread. While majority of people stay in close geographical boundaries like cities, towns and villages some inhabitants do reside in remote areas. Reaching such sparse and inaccessible areas possess various challenges. Some banks like SBI have shown audacity in opening branches in remote localities, they have been mostly part of Corporate Social Responsibility (CSR) and not justifiable in business sense. Our model allows banks to provide their service where only a single branch may suffice the need of the public. Since the cost of operating a branch for a single bank will be equivalent to operating the branch for multiple banks, it will not possess any economical hindrance in elevating the branch status to 'all bank branch'.

Sometimes bank may only require a nominal branch, only for the purpose of information dissemination or to cater to an occasional visitor or a tourist, for that purpose having either an independent branch or even a POS terminal may not be viable. The model allows banks to reach and cater so such sporadic needs without having to spend upfront for infrastructure.

\subsection{Trial Run and Demo Establishments}

If bank wants to first find out if a given location, remote or otherwise, will be profitable enough then currently it has no means to do the same. It has to put money into infrastructure, which are mostly irrevocable, sunk and immovable. This restricts bank from venturing into places where it might not be fully sure of attracting enough customers. Our model allows banks to have trial runs or even demo establishments with very minimal cost. Based on results bank would be free to decide on opening its own branch and avoid taking precarious risks.

\section{ISSUES AND FURTHER ENHANCEMENTS}

Even though the model proposes to reduce the business and transaction cost by manifold there is no discounting that acceptance to the model will take some stirring and revaluation of banking growth. There could be some concerns with respect to security, which has been dealt in 3.1.2Security.

Based on more stringent regulations more layers of security could be introduced like providing a RSA Secure ID token card to customers. Every transaction initiated from the interface would need the value of RSA Secure token [14]; this will ensure no unsolicited transactions are ever parsed.

Concerns related to cash and physical security could be dealt by having more strict policy in terms of liquidity management. Requiring higher collateral and security deposit if the Interface provider is any organization outside the trust circle of the bank.

One important enhancement could be 'interoperability of interbank customer accounts' and seamless multibank transactions. While RBI has provided NEFT/RTGS for interbank transactions they are nationally settled and come with higher integration cost along with some time cost.

In the event of liquidity crunch at particular branch/bank or in the unfortunate case of 'bank runs' [15] when there is severe pressure on liquidity of particular bank exuberated due to customer's irrational need to withdraw their money in exodus, our model will help keep the bank afloat by allowing interbank liquidity management.

\section{CONCLUSION}

We have proposed and presented a model which will allow the banks to have a common branch, share the infrastructure, reduce the cost and cater to customers of all banks. Currently the advent of mBanking and eBanking has been rift with technological, social and economic issues. Limitations of nonbranch Point of Service have deterred the growth of ATMs and Internet Kiosks. 
Our model meets the goal of low-cost by drastically reducing the number of branches required, sharing the infrastructure and allowing the 'economics of scale' to take advantage of higher transactions when cumulated across banks.

Our proposal of using common banking interface, dynamically switching the IP to the provider bank's API, connecting securely to bank's network and completing the transaction is very simple, feasible with existing bank setups and doesn't require customer to achieve higher degree of tolerance towards any new technology.

We have shown that this model will save cost, be reliable, help scale up banking needs, have wide reach, make banking more service oriented and encourage banking innovations. We have also addressed possible sources of concern viz., security, competition and trust issues. We have also shown why it may not be in bank's advantage to have their own branch across the state and why sharing the branches will benefit them all.

\section{REFERENCES}

[1] Mas, Ignacio, The Economics of Branchless Banking (April 1, 2009). Innovations, Vol. 4, No. 2, 2009.

[2] Debashis Chakraborty and Arup Guha, Infrastructure and Economic Growth in India: Analyzing the Village-level Connectivity Scenario of the States, Journal of Infrastructure Development June 2009 1: 67-86.

[3] Dr. Chakrabarty, K.C, Pushing Financial Inclusion Issues, Challenges and Way Forward, RBI (July 17, 2009).

[4] Amila Karunanayake, Kasun De Zoysa, and Sead Muftic. 2008. Mobile ATM for developing countries. In Proceedings of the 3rd international workshop on Mobility in the evolving internet architecture (MobiArch '08). ACM, New York, NY, USA, 25-30.

[5] Trung Dong Huynh, Nicholas R. Jennings, and Nigel R. Shadbolt. 2006. Certified reputation: how an agent can trust a stranger. In Proceedings of the fifth international joint conference on Autonomous agents and multiagent systems (AAMAS '06). ACM, New York, NY, USA, $1217-1224$
[6] A. Seth, D. Kroeker, M. Zaharia, S. Guo, and S. Keshav. 2006. Low-cost communication for rural internet kiosks using mechanical backhaul. In Proceedings of the 12th annual international conference on Mobile computing and networking (MobiCom '06). ACM, New York, NY, USA, 334-345.

[7] Vânia Gonçalves, Pieter Ballon, Adding value to the network: Mobile operators' experiments with Softwareas-a-Service and Platform-as-a-Service models, Telematics and Informatics, Volume 28, Issue 1, February 2011, Pages 12-21, ISSN 0736-5853.

[8] Nitin Munjal, Ashish Paliwal, Rajat Moona. (Mar, 2009). Low Cost Secure Transaction Model for Financial Services. In Ultra-Modern Telecommunications \& Workshops, 2009. ICUMT '09.

[9] Cordella, Antonio (July, 2006), Transaction costs and information systems: does IT add up?, Journal of Information Technology (2006) 21, 195-202

[10] Tomassini Marco, Luthi Leslie, Giacobini Mario (2006), Hawks and Doves on small-world networks, The American Physical Society.

[11] Hardin, G (1968), The Tragedy of Commons, M.E. Sharpe.

[12] Burgess, Robin and Pande, Rohini, Do Rural Banks Matter? Evidence from the Indian Social Banking Experiment (August 2003)., Vol., pp. -, 2003.

[13] BB Stewart, J Thompson (2004), Distributed network communication system which enables multiple network providers to use a common distributed network infrastructure, US Patent 6,732,176.

[14] Ginter, Karl L, Shear, Victor H, Sibert, Olin W, Spahn, Francis J, Van Wie, David M, Systems and methods for secure transaction management and electronic rights protection, US Patent 5892900.

[15] Hyun Song Shin, Reflections on Northern Rock: The Bank Run That Heralded the Global Financial Crisis, The Journal of Economic Perspectives, Vol. 23, No. 1 (Winter, 2009), pp. 101-120. 